\title{
Dampak Keberadaan Lembaga Hukum Adat Laot Dalam Kehidupan Nelayan Aceh Terhadap Tingkat Pendapatan Nelayan (Studi kasus: Pada masyarakat nelayan di Kabupaten Barat Provinsi Nanggroe Aceh Darussalam)
}

\author{
Impact of Costumary Law Sea (Law Laot) Institute On The Live Of \\ Aceh Fishermen On The Income Level \\ (Study case: Fisherment community in West Aceh District, Aceh Province)
}

\author{
Eva Wardah \\ Program Studi Agribisnis Fakultas Pertanian Universitas Malikussaleh \\ Kampus Cot Teungku Nie, Reuleut, Muara Batu Aceh Utara 24355, Indonesia \\ Email:eva.pwd@gmail.com
}

Diterima 21 Juli 2014; Dipublikasi 1 September 2014

\begin{abstract}
Abstrak
Masalah yang dikaji dalam studi ini diarahkan pada Dampak keberadaan Lembaga Hukum Adat Laot sebagai salah satu model pengelolaan perikanan berbasis masyarakat yang masih tetap eksis dalam lingkungan nelayan Aceh untuk dapat memberikan manfaat terhadap peningkatan pendapatan nelayan. Berdasarkan hasil analisa data yang digunakan dalam penelitian ini secara umum peran LHAL belum efektif dalam kehidupan masyarakat nelayan, sehingga pemerintah dirasa perlu memberikan perhatian serius kepada nelayan dalam hal penyediaan sarana dan prasarana penangkapan yang lebih baik sehingga dapat meningkatkan hasil tangkapan yang berdampak terhadap peningkatan pendapatan. Usaha yang dilakukan diantaranya penguatan kelembagaan Panglima Laot dengan cara mengefektifkan kelembagaan dan berupaya meningkatkan pemahaman nelayan tentang Lembaga Hukum Adat Laot.
\end{abstract}

Kata kunci: lembaga hukum adat laot, nelayan, peningkatan pendapatan

\begin{abstract}
Issues examined in this study is directed to the impact of the presence Customary Law Laot Institute as one model of community-based fisheries management that still exist within the Aceh fishermen to be able provide benefits increase the income of fishermen. Based on the analysis of the data used in this study are generally not effective LHAL role in the life of fishing communities, so that the government deemed necessary to give serious attention to the fishermen in the provision of facilities and infrastructure better arrest so as to increase the catch which resulted in increased income. The work done including institutional strengthening Laot by way of effecting institutional and seeks to increase understanding the Institute of Customary Law fishermen Laot.
\end{abstract}

Keyword: customary law laot institute, fisherman, income improvement

\section{Pendahuluan}

Sumber daya perikanann disekitar pantai barat Aceh yang dapat dijangkau oleh nelayan kecil sebenarnya tergolong rendah potensinya, apabila dibandingkan dengan potensi perikanan diwilayah perairan Aceh lainnya. Jumlah penduduk yang relative padat serta kemampuan yang rendah dengan sifat "open acces" sumberdaya perikanan yang tampak semakin mengarah kepada terjadinya pengurasan sumberdaya perikanan sebagai akibat dari padatnya tingkat tangkapan didaerah tersebut. Padahal sumberdaya tersebut merupakan mata pencaharian utama bagi nelayan tradisional. Terlebih lagi rendahnya tingkat pendidikan, keterbatasan penguasaan modal/capital,rendahnya teknologi yang digunakan serta kurangnya mobilitas yang ada semakin mendorong kearah yang sangat memprihatinkan sehingga aspirasi masyarakat juga rendah sebagai akibat bawaan dari budaya tradisional. Demikian juga kelembagaan tradisional yang ada sering tidak memberikan peluang untuk dapat memperbaiki situasi ini. 
Sehingga secara keseluruhan belum mampu mendukung terjadinya perbaikan hidup dan tingkat kesejahteraan masyarakat nelayan.

Kelembagaaan tradisional dipandang perlu sebagai sebagai sebuah pilar penting dalam memperkuat struktur kelembagaan guna menyelaraskan seluruh aspek dari keragaan pembangunan sektor kelautan dan perikanan itu sendiri. Salah satu lembaga tradisional yang berbasis pada hukum adat yang berhubungan dengan bidang kelautan dan perikanan di Indonesia adalah Lembaga Hukum Laot (LHAL) yang terdapat di Provinsi Nanggroe Aceh Darussalam.

Peranan Lembaga Hukum Adat Laut dalam masyarakat Aceh memandang Panglima Laot sebagai pemimpin lembaga adat. Sebagai suatu lembaga adat, maka lembaga adat tersebut berkuasa mengatur eksploitasi lingkungan laut didalam wilayah laut yang menjadi kekuasaannya. Kekuasaan mengatur lingkungan laut yang bersifat otonom serta tidak tergantung kepada kekuasaan manapun juga. Kekuasaan Panglima Laot meliputi tiga bidang yaitu bidang keamanan laut, bidang sosial warga, persekutuan dan bidang pemeliharaan lingkungan laut.

Faktor kedudukan dan keberadaan LHAL ini tertuang dalamng pasal 6 Peraturan Daerah Provinsi Nanggroe Aceh Darussalam No 2 Tahun 1990 tentang Pembinaan Adat dan Pengembangan Adat Istiadat. Hukum Adat Laot mempunyai tugas antara lain :

1. Memelihara dan mengawasi ketentuanketentuan Hukum Adat Laot.

2. Mengkoordinasikan dan mengawasi setiap usaha penangkapan ikan dilaut.

3. Menyelesaikan perselisihan/sengketa yang terjadi antara sesama nelayan atau kelompoknya.

4. Menggurus dan menyelenggarakan upacara adat laot.

5. Menjaga dan mengawasi agar pohon-pohon ditepi sungai tidak ditebang (dikarnakan ikan akan menjauh sampai ketengah laut dan disesuaikan dengan kondisi dan situasi daerah setempat).

6. Merupakan badan penghubung antara nelayan dan pemerintah.

7. Meningkatkan taraf hidup masyarakat nelayan.

8. Mengatur jadwal ritual yang berhubungan dengan masyarakat nelayan (misalnya: khanduri Laot).
Berdasarkan latar belakang tersebut diatas, maka diperlukan suatu analisa dampak keberadaan Lembaga Hukum Adat Laot dalam kehidupan masyarakat nelayan aceh kaitannya terhadap tingkat pendapatan masyarakat nelayan dikabupaten Aceh Barat. Hal yang mendasar bahwa sebelum terjadinya perubahan Lembaga Hukum Laot ini mampu mengelola sumberdaya perikanan menjadi lebih bermanfaat dan adil dalam memberikan kesempatan kepada masyarakat nelayan yang disatu sisi berdampak terhadap tingkat kesejahteraan masyarakatnya dan disisi lain bertujuan mengelola sumberdaya perikanan yang sustainable di wilayah kabupaten Aceh Barat.

Masalah yang dikaji dalam penelitian ini diarahkan kepada peran dari Lembaga HUkum Adat Laot (LHAL) dalam kehidupan nelayan aceh dalam menjaga dan mengatur setiap usaha penangkapan ikan yang dilakukan nelayan setempat sebagai mata pencaharian utama mereka, disamping itu juga bersaing dengan nelayan-nelayan asing yang menggunakan peralatan tangkap yang canggih yang berdampak terhadap tingkat hasil tangkapan yang diperoleh nelayan yang pada akhirnya berdampak juga terhadap tingkat pendapatan nelayan.

Untuk mengkaji studi ini dipilih kasuskasus yang terjadi dalam Lembaga Hukum Adat Laot (LHAL), dengan alasan karena Lembaga Hukum Adat Laot ini merupakan lembaga perikanan yang masih eksis dalam kehidupan nelayan aceh.

Tujuan dari penelitian ini adalah untuk mengkaji seberapa besar dampak keberadaan Lembaga Hukum Adat Laot (LHAL) dalam kehidupan nelayan aceh kaitannya terhadap tingkat pendapatan nelayan di daerah ini, sedangkan tujuan khusus dari penelitian ini adalah:

1. Menganalisa peran dari Lembaga Hukum Adat Laot (LHAL) dalam kehidupan masyarakat nelayan aceh kaitannya dengan tingkat pendapatan masyarakat nelayan.

2. Menganalisa faktor-faktor apa saja yang mempengaruhi tingkat pendapatan masyarakat nelayan diwilayah perairan Aceh Barat.

3. Menganalisa hubungan kelembagaan perikanan antara nelayan dengan tauke yang ada di kawasan perairan Aceh Barat.

4. Menganalisa kelayakan investasi untuk setiap jenis alat tangkap yang digunakan nelayan dilokasi penelitian. 


\section{Metode Penelitian}

Lokasi penelitian dilakukan di Aceh Barat Provinsi Nanggroe Aceh Darussalam yang meliputi 2 kecamatan di 6 (enam) desa nelayan. Alasan pengambilan lokasi penelitian ini adalah karena desa -desa ini merupakan desa nelayan dengan tingkat sosial ekonominya yang masih sangat rendah, selain itu juga desa-desa tersebut merupakan desa pantai dan mempunyai kuala (muara) sehingga ada kelembagaan panglima laot disana yang berfungsi sebagai pelaksana hukum adat laot yang ada didesa tersebut.

Lokasi penelitian ditetapkan di dua kecamatan dalam kabupaten Aceh Barat yaitu kecamatan Johan Pahlawan meliputi desa padang seurahet,desa panggong dan desa kampong pasir serta kecamatan meurebo yang meliputi desa Meurebo, Desa Langgung dan Desa Ujong Drien.

Data yang dibutuhkan dalam penelitian ini adalah data primer dan data sekunder, data primer diperoleh dari responden dan informan yang telah ditentukan melalui pengamatan langsung di lapangan. Data sekunder diperoleh dari laporan-laporan penelitian terdahulu, tulisan-tulisan ilmiah serta peraturan perundangundangan yang berhu-bungan dengan keberadaan Lembaga Hukum Adat Laot.

\section{Analisa Data}

\section{Analisa Korelasi Spearman}

Untuk mengetahui sejauh mana hubungan peran Lembaga Hukum Adat Laot (LHAL) berpengaruh terhadap tingkat pendapatan nelayan diKabupaten Aceh Barat dengan menggunakan system skor uji statistik yang dibagi atas tiga kategori yaitu rendah, sedang dan tinggi. Penentuan tiap kategori menggunakan rumus umum sebaran normal yaitu :

1. Rendah, bila lebih kecil dari $\mathrm{X}$ - standar deviasi atau X - Sd

2. Sedang, bila sama dengan $X \pm$ standar deviasi atau $\mathrm{X} \pm 1 / 2 \mathrm{Sd}$

3. Tinggi, bila lebih besar dari $X+$ standar deviasi atau $\mathrm{X}+1 / 2 \mathrm{Sd}$

\section{Analisis Regresi Linier}

Analisis Regresi Linier digunakan untuk mengetahui faktor yang ikut mempengaruhi tingkat pendapatan nelayan dikabupaten Aceh
Barat dengan mengidentifikasi berbagai peubah terutama yang berkaitan dengan pendapatan.

Secara matematis hubungan antara tingkat pendapatan dengan variable regresi yang diuji dalam penelitian ini adalah:

$\mathrm{Y}=\mathrm{f}(\mathrm{X} 1.1, \mathrm{X} 1.2, \mathrm{X} 1.3, \mathrm{X} 1.4, \mathrm{X} 1.5, \mathrm{X} 1$.

\section{Analisa pendapatan dan produktivitas kerja} nelayan

Analisa yang digunakan adalah berdasarkan jenis-jenis alat tangkap yang digunakan nelayan di wilayah penelitian. Dengan menggunakan analisa biaya manfaat serta analisa indeks probabilitas modal.

\section{Analisa financial}

Untuk mengetahui kriteria penilaian investasi suatu usaha penangkapan ikan dengan menghitung Net Present Value (NVP),Internal Rate of Return (IRR), dan Benefit Cost Ratio (B/C).

\section{Analisa Kelembagaan}

Untuk mengkaji faktor-faktor yang mempengaruhi pola dan peran kelembagaan dalam pengaturan pemanfaaatan sumberdaya perikanan secara lestari sehingga mendukung kelancaran aktifitas kelembagaan dengan tetap memperhatikan faktor-faktor seperti kondisi sosial ekonomi desa pantai serta kebijakankebijakan dari program pemerintah setempat.

\section{Hasil dan Pembahasan}

\section{Peran LHAL Dalam Kehidupan Nelayan Aceh}

Dari tabel menunjukkan bahwa sepertiga lebih responden mempunyai persepsi yang rendah terhadap peran LHAL sebagai badan penghubung antara nelayan dengan pemerintah, sedangkan sepertiga berikutnya nelayan mempunyai persepsi yang baik dan selisihnya nelayan mempunyai persepsi yang sedang. Hal ini menunjukkan bahwa peran LHAL sebagai badan penghubung antara nelayan dengan pemerintah belum optimal dapat dilakukan. 
Tabel 1. Distribusi responden terhadap peran LHAL sebagai badan penghubung antara nelayan dengan pemerintah

\begin{tabular}{|c|c|c|c|c|}
\hline No & $\begin{array}{c}\text { Peran LHAL } \\
\text { sebagai Badan } \\
\text { Penghubung antara } \\
\text { nelayan dengan } \\
\text { pemerintah } \\
\end{array}$ & Responden & Persen & $\begin{array}{l}\text { atau ketika musim barat akan berakhir. } \\
\text { Pencarian dana untuk prosesi khanduri laot } \\
\text { ukan suatu hal yang memberatkan atau } \\
\text { paksaan. Masyarakat menilai bahwa iuran } \\
\text { tersebut merupakan kewajiban untuk }\end{array}$ \\
\hline 1 & Rendah & 44 & $36,67 \%$ & omnyisih-kan sebagian penghasilan sebagai \\
\hline 2 & Sedang & 35 & & $\begin{array}{l}\text { ungkapan pasrtisipasi karena telah menjadi } \\
\text { tradisi secara turun temurun, bahkan }\end{array}$ \\
\hline 3 & Tinggi & 41 & $34,17 \%$ & $\%$ partisipasi terebut bukan hanya berasal dari \\
\hline \multicolumn{2}{|c|}{ jumlah } & 120 & $100,00 \%$ & nasyarakat yang bukan \\
\hline
\end{tabular}

Dari tabel 2 menunjukan bahwa sebanyak 49 responden nelayan mempunyai persepsi yang tinggi terhadap peran LHAL dalam hal penyelesaikan sengketa yang terjadi antar nelayan, hal ini menurut hasil penelitian kebanyakan sengketa-sengketa yang terjadi antara nelayan selalu dapat diselesaikan melalui peradilan yang ada pada Lembaga HUkum Adat Laot tampa harus diselesaikan kepada pihak yang berwajib. Hal ini disebabkan karena nelayan masih percaya kepada putusan-putusan atau sangsi yang telah ditetapkan dilembaga Hukum Adat Laot dan nelayan juga masih sangat yakin bahwa sangsi-sangsi yang diberikan tidak memberatkan pihak manapun.

Dari tabel Tabel 3 menunjukan bahwa hampir setengah responden mempunyai persepsi sedang terhadap peran LHAL dalam hal mengurus upacar adat laot, sedangkan selebih-nya nelayan masih memiliki persepsi yang rendah, kondisi ini tergambar dari pengamatan penulis dilapangan bahwa nelayan tidak lagi merasakan manfaat dari penyelenggaraan upacara adat laot karena berbau animisme.

Sedangkan sebanyak $30 \%$ responden mempunyai persepsi yang tinggi terhadap peran LHAL dalam hal menyelenggarakan upacara adat dengan melibatkan seluruh komponen masyarakat nelayan Bagi masyarakat nelayan aceh khanduri laot merupakan upacara menjelang musim timur Pencarian dana untuk prosesi khanduri laot ukan suatu hal yang memberatkan atau paksaan. Masyarakat menilai bahwa iuran tersebut merupakan kewajiban untuk ungkapan pasrtisipasi karena telah menjadi tradisi secara turun temurun, bahkan nelayan pun juga turut menyumbang.

\section{Analisis Korelasi Spearman}

Hasil analisis korelasi Spearman menunjukkan hubungan antar tingkat pendapatan dengan peran Lembaga Hukum Adat Laot (LHAL) yang diamati dalam penelitian ini diantaranya: 1) sebagai badan penghubung antar nelayan, 2) menyelesaikan sengketa antar nelayan, 3) mengurus dan menyelenggarakan upacara adat laot, maka dapat disimpulkan bahwa hanya peran LHAL dalam penyelesaian sengketa yang terjadi antar nelayan yang ber-pengaruh terhadap tingkat pendapatan nelayan pada taraf kepercayaan $0,5 \%$, sedangkan peran LHAL sebagai badan penghubung antara nelayan dengan pemerintah dan peran LHAL dalam hal mengurus dan menyelenggarakan upacara adat laot tidak berpengaruh terhadap tingkat pendapatan yang diperoleh nelayan. berikut dapat dilihat hasil analisis korelasi Spearman (Tabel 4).

Faktor-faktor yang mempengaruhi tingkat pendapatan nelayan

Dalam penelitian ini faktor-faktor yang mempengaruhi tingkat pendapatan nelayan dilakukan dengan menggunakan analisis regresi linier berganda. 
Tabel 2. Distribusi responden terhadap peran LHAL dalam menyelesaikan sengketa antara nelayan

\begin{tabular}{llcc}
\hline No & $\begin{array}{c}\text { Peran LHAL dalam menyelesaikan } \\
\text { sengketa antar nelayan }\end{array}$ & Responden & Persen \\
\hline 1 & Rendah & 49 & $40,83 \%$ \\
2 & Sedang & 22 & $18,33 \%$ \\
3 & Tinggi & 49 & $40,33 \%$ \\
\hline Jumlah & 120 & $100,00 \%$ \\
\hline
\end{tabular}

Sumber: Data primer dan kuesioner (diolah)

Tabel 3. Distribusi responden terhadap peran LHAL dalam mengurus dan menyelenggarakan Upacara Adat Laot

\begin{tabular}{cccc}
\hline No & Peran LHAL dalam mengurus upacara adat laot & Responden & Persen \\
\hline 1 & Rendah & 33 & $27,5 \%$ \\
2 & Sedang & 51 & $42,5 \%$ \\
3 & Tinggi & 36 & $30,0 \%$ \\
\hline Jumlah & & 120 & $100,00 \%$ \\
\hline
\end{tabular}

Sumber: Data primer dan kuesioner (diolah)

Adapun peubah yang diperhitungkan adalah: 1)>pengalaman berusaha nelayan, 5) jumlah anggota rumah tangga nelayan, 6) keterbukaan terhadap informasi, 7) persepsi terhadap LHAL. Hasil penelitian dapat dilihat pada Tabel 5. Dari tabel dapat dijelaskan bahwa faktor umur dengan nilai P- value 0.493 ( $>$ dari $\alpha=10 \%$ ), ini menunjukan bahwa factor umur nelayan tidak berpengaruh nyata secara statistic terhadap tingkat pendapatan nelayan.ini menunjukan bahwa faktor umur tidak memberikan kontribusi yang sangat berarti pada setiap jenjang usia. Usia nelayan dalam penleitian ini berada dalam kategori usia yang produktif (sebaran 18 - 55). Hal ini senada dengan konsep batasan umur kerja produktif menurut Kartini, K ( 1994 ).

Besarnya P-Value dari faktor tingkat pendidikan adalah 0.000 yaitu lebih kecil $\alpha=$ $10 \%$.ini menunjukan bahwa tingkat pendidikan nelayan secara statistik mempengaruhi tingkat pendapatan yang diperoleh nelayan,semakin tinggi tingkat pendidi kan akan berpengaruh terhadap tingkat pendapatannya. Faktor pengalaman berusah didapat $\mathrm{P}-$ Value sebesar 0,007 , ini menunjukan bahwa faktor pengalaman berusaha nelayan ber-pengaruh nyata dimana semakin tinggi penga-laman seorang nelayaan dalam kegiatan opera-sional penangkapan ikan maka akan mening-katkan produktivitas sekaligus berdampak terhadap peningkatan pendapatan yang diper-oleh nelayan.

Faktor jumlah anggota rumah tangga nelayan didapat P-Value sebesar 0,000 artinya faktor jumlah anggota rumah tangga nelayan sangat berpengaruh nyata,artinya semakin banyak julah anggota rumah tangga nelayan maka akan berpengaruh trehadap tingkat penapatan yang diperoleh.

Faktor keterbukaan terhaap informasi dengan nilai $\mathrm{P}$-Value sebesar 0,080 , ini menunjukan bahwa faktor ini tidak berpengaruh nyata. Kondisi ini dipengaruhi oleh sdikitnya informasi tentang inovasi penangkapan ikan serta minat baca,sedangkan hasil analisa tentang persepsi terhadap LHAL pengaruhnya terhadap tingkat pendapatan dengan nilai $\mathrm{P}$ Value sebesar 0,232, ini menunjukan bahwa persepsi nelayan terhadap LHAL tidak berpengaruh nyata. 
Tabel 4. Analisis Korelasi Spearman terhadap peran LHAL

\begin{tabular}{|c|c|c|c|c|c|c|}
\hline & & & $\begin{array}{c}\text { Badan } \\
\text { penghubung } \\
\text { antara nelayan } \\
\text { dgn pemerintah }\end{array}$ & $\begin{array}{c}\text { Menyelesaikan } \\
\text { sengketa antar } \\
\text { nelayan }\end{array}$ & $\begin{array}{l}\text { Menggurus dan } \\
\text { menyelenggaraka } \\
\text { upacara adat laot }\end{array}$ & Pendapatan \\
\hline \multirow[t]{4}{*}{ Spearman's } & $\mathrm{X} 21$ & $\begin{array}{l}\text { Badan penghubung } \\
\text { antara nelayan } \\
\text { dengan pemerintah }\end{array}$ & 1.000 & $\begin{array}{c}0,23 \\
(802)\end{array}$ & $\begin{array}{c}-0,77 \\
(401)\end{array}$ & $\begin{array}{c}-134 \\
(146)\end{array}$ \\
\hline & $\mathrm{X} 22$ & $\begin{array}{l}\text { Menyelesaikan } \\
\text { sengketa antar } \\
\text { nelayan }\end{array}$ & $\begin{array}{l}0,23 \\
(802\end{array}$ & 1.000 & $\begin{array}{l}-144 \\
(117)\end{array}$ & $\begin{array}{c}183 \\
(046)\end{array}$ \\
\hline & $\mathrm{X} 23$ & $\begin{array}{l}\text { Menggurus an } \\
\text { menyelenggarakan } \\
\text { upacara adat laot }\end{array}$ & $\begin{array}{c}0,77 \\
(401)\end{array}$ & $\begin{array}{c}-144 \\
(117)\end{array}$ & 1.000 & $\begin{array}{r}-0,75 \\
(419)\end{array}$ \\
\hline & Y & Pendapatan & $\begin{array}{c}134 \\
(146)\end{array}$ & $\begin{array}{c}183 \\
(046) \\
\end{array}$ & $\begin{array}{r}-0,75 \\
(419) \\
\end{array}$ & 1.000 \\
\hline
\end{tabular}

Correlation is significant at the 05 level (2 tailed); ( ) Probability Value

Tabel 5. Hasil analisis regresi linier dari masing - masing variable yang terkait dengan pendapatan.

\begin{tabular}{lrr}
\hline \multicolumn{1}{c}{ Variabel Peubah } & Koefisien Regresi & P - Value \\
\hline X11 Umur & -2950 & 0.493 \\
X12 Tingkat Pendidikan & 185931 & 0.000 \\
X13 Pengalaman berusaha nelayan & 11496 & 0.007 \\
X14 Jumlah Anggota RTP & 104101 & 0.000 \\
X15 Keterbukaan terhadap informasi & 20064 & 0.080 \\
X16 Persepsi terhadap LHAL & 16664 & 0.232 \\
\hline Constant & -20061 & 0.965 \\
\hline
\end{tabular}

\section{Kajian Kelembagaan Perikanan}

\section{Permodalan}

Tabel 6. Rata-rata modal usaha nelayan menurut lokasi penelitian, 2004.

\begin{tabular}{lccc}
\hline \multirow{2}{*}{ Lokasi penelitian } & \multicolumn{2}{c}{ Modal Usaha (ribuan rupiah ) } & Jumlah (Rp/ unit) \\
\cline { 2 - 3 } & Armada / alat lainnya & Alat Tangkap & \\
\hline Padang Seurahet & 6.000 & 4.120 & 10.120 \\
Kp.Pasir & 5.150 & 3.852 & 9.002 \\
Panggong & 5.870 & 2.309 & 8.179 \\
\hline Rata -rata & 5.673 & 2.760 & 8.433 \\
\hline Meurebo & 4.530 & 2.780 & 7.310 \\
Ujong drien & 5.000 & 3.000 & 8.000 \\
Langgung & 5.000 & 3,150 & 8.150 \\
\hline Rata - rata & 4.843 & 2.976 & 7.819 \\
\hline
\end{tabular}

Sumber: data primer 
Tabel 7. Sumber modal nelayan dilokasi penelitian

\begin{tabular}{llcccccc}
\hline \multirow{2}{*}{ No } & \multirow{2}{*}{ Desa } & \multicolumn{3}{c}{ Sumber Modal } & Jumlah \\
\cline { 3 - 7 } & Pribadi & $\begin{array}{c}\text { Toke } \\
\text { bangku }\end{array}$ & Bank & Koperasi & Pedagang & \\
\hline 1 & Padang Seurahet & $12(21.8)$ & $4(11.1)$ & $1(11.1)$ & 0 & $3(18.75)$ & 20 \\
2 & KP.Pasir & $9(16.3)$ & $6(16.6)$ & $3(33.3)$ & 0 & $2(12.5)$ & 20 \\
3 & Panggong & $7(12.7)$ & $4(11.1)$ & $2(22.2)$ & $3(75.0)$ & $4(25.0)$ & 20 \\
4 & Meurebo & $11(20.0)$ & $5(41.6)$ & $2(22.2)$ & 0 & $2(12.5)$ & 20 \\
5 & Ujong Drien & $10(18.1)$ & $6(61.6)$ & 0 & $1(25.0)$ & $3(18.7)$ & 20 \\
6 & Langgung & $6(10.9)$ & $11(30.5)$ & $1(11.1)$ & 0 & $2(12.5)$ & 20 \\
\hline & Jumlah & 55 & 36 & 9 & 4 & 16 & 120 \\
\hline
\end{tabular}

Sumber: data primer

Keterangan : tanda ( ) menunjukan persentase

Tabel 8. Lembaga-lembaga pemasaran hasil tangkapan para nelayan

\begin{tabular}{llcccccc}
\hline \multirow{2}{*}{ No } & Desa Penelitian & \multicolumn{6}{c}{ Lembaga Pemasaran } \\
\cline { 3 - 6 } & Pasar desa & $\begin{array}{c}\text { Toke } \\
\text { bangku }\end{array}$ & Muge & TPI & Koperasi & \\
\hline 1 & Padang Seurahet & 4 & 38 & 18 & 1 & 5 & 66 \\
2 & Kp.Pasir & 2 & 18 & 8 & - & 1 & 29 \\
3 & Pangong & 2 & 8 & 10 & - & 3 & 23 \\
4 & Meurebo & 4 & 19 & 14 & - & 2 & 39 \\
5 & Ujong Drien & 2 & 6 & 8 & - & 1 & 17 \\
6 & Langgung & 1 & 2 & 2 & - & 1 & 6 \\
\hline & Jumlah & $15(8,3)$ & $91(50.5)$ & $60(33.4)$ & $1(0.5)$ & $13(7.2)$ & 180 \\
& & & & & & & $(100)$ \\
\hline
\end{tabular}

Sumber: Hasil survey desa dan kuesioner

Keterangan: tanda ( ) menunjukan persentase

Tabel 9. Kendala yang dihadapi nelayan dalam pemasaran hasil tangkapan.

\begin{tabular}{llcccccc}
\hline \multirow{2}{*}{ No } & Desa Penelitian & $\begin{array}{c}\text { Harga } \\
\text { ditentukan } \\
\text { pedagang }\end{array}$ & $\begin{array}{c}\text { Harga } \\
\text { murah }\end{array}$ & $\begin{array}{c}\text { Harga } \\
\text { tidak } \\
\text { stabil }\end{array}$ & Pasar jauh & $\begin{array}{c}\text { Sulitnya } \\
\text { mencari } \\
\text { angkutan }\end{array}$ & Jumlah \\
\hline 1 & Padang Seurahet & 15 & 2 & 3 & - & - & 20 \\
2 & Kp.Pasir & 11 & 3 & 3 & 2 & 1 & 20 \\
3 & Panggong & 8 & 7 & 5 & 3 & - & 20 \\
4 & Meurebo & 5 & 9 & 4 & 2 & - & 20 \\
5 & Ujong Drien & 4 & 4 & 7 & 3 & 2 & 20 \\
6 & Langgung & 5 & 2 & 3 & 4 & 6 & 20 \\
\hline & Jumlah & $48(40)$ & $27(22.5)$ & $25(20.8)$ & $11(9.16)$ & $9(7.5)$ & 120 \\
\hline
\end{tabular}

Sumber: Hasil survey desa dan kuesioner (diolah)

Keterangan: tanda ( ) menunjukan persentase 
Tabel 10. Alasan nelayan memilih melakukan transaksipenjualan ikan dengan tauke, 2004.

\begin{tabular}{|c|c|c|c|c|}
\hline \multirow[b]{2}{*}{ Lokasi penelitian } & \multicolumn{4}{|c|}{ Alasan Nelayan } \\
\hline & Harga lebih tinggi & $\begin{array}{l}\text { Terikat } \\
\text { hutang }\end{array}$ & $\begin{array}{l}\text { Tidak ada pembeli } \\
\text { lain }\end{array}$ & Timbangan lebih adil \\
\hline Kec. Johan pahlawan & & & & \\
\hline - Padang Seurahet & 11 & 21 & - & 7 \\
\hline - Kp.Pasir & 7 & 3 & - & - \\
\hline - Panggong & 4 & 7 & - & - \\
\hline Jumlah & $22(36.67)$ & $31(51.67)$ & - & $7(11.37)$ \\
\hline Kec. Meurebo & & & & \\
\hline - Meurebo & 5 & 2 & 15 & - \\
\hline - Ujong Drien & 4 & 4 & 6 & - \\
\hline - Langgung & 7 & 13 & 4 & - \\
\hline Jumlah & $16(26.67)$ & $19(31.67)$ & $25(41.670$ & - \\
\hline
\end{tabular}

Sumber : Hasil survey desa dan kuesioner (diolah)

Keterangan : tanda ( ) menunjukan persentase

\section{Kelayakan Usaha Finasial}

\section{Analisis Kelayakan Finansial}

Berdasarkan nilai indikator tersebut diinterpretasikan bahwa untuk keempat jenis alat tangkap yang digunakan nelayan secara financial layak untuk digunakan, terlihat bahwa untuk jenis alat tangkap besarap jaringnya $\mathrm{B} / \mathrm{C}$ ratio 1,64 artinya nilai $\mathrm{B} / \mathrm{C}$ lebih besar dari pada 1,sedangkan Nilai Internal Rate of Return untuk jenis alat tangkap jarring teryata lebih besar dibandingkan dengan tingkat bunga pinjaman (Tabel 11).

\section{Analisis Kebijakan}

Penggunaan Policy Analisis Matrix (PAM) kelayakan usaha penangkapan ikan oleh nelayan dapat diketahui dengan melihat keuntungan privat dan keuntungan social (Tabel 12). Hasil dari Tabel 12 secara finansial keseluruhan jenis alat tangkap cukup memberikan keuntungan bagi nelayan, walaupun demikian derajat keuntungan yang ditimbulkan berbeda dari masing-masing jenis alat tangkap.
Ada kecendrungan bahwa tinggi investasi modal yang dibutuhkan bagi suatu jenis alat tangkap justru indeks probabilitasnya semakin menurun. Alat tangkap jaring yang relatif tinggi.

Dari Tabel 13 dapat dilihat bahwa nilai relative share upah bagi masing - masing jenis alat tangkap menunjukan kisaran cenderung tidak berbeda disemua wilayah penelitian. Angka - angka relative share upah berkisar antara 30$35 \%$.berdasarkan hasil analisa data tersebut menunjukan bahwa nagian hasil yang diterima nelayan cukup memadai.

Berdasarkan Tabel 14 diatas dijelaskan bahwa keragaman rata-rata tingkat pendapatan lebih banyak disebabkan oleh perbedaan teknologi alat tangkap yang digunakan. Sejalan dengan hasil penelitian teryata tingkat pendapatan rata - rata nelayan diwilayah Kabupaten Aceh Barat masih sangat rendah dibandingkan nelayan di wilayah Aceh lainnya. 
Tabel 11. Nilai Indikator Finansial usaha penangkapan ikan berdasarkan jenis alat tangkap yang digunakan nelayan

\begin{tabular}{lrrrr}
\hline Uraian & \multicolumn{4}{c}{ Jenis Alat Tangkap } \\
\cline { 2 - 5 } & \multicolumn{1}{c}{ Jaring } & \multicolumn{1}{c}{ Pancing } & \multicolumn{1}{c}{ Pukat } \\
\hline Investasi & 4.179 .000 & 8.775 .000 & 30.685 .000 & 4.455 .000 \\
Penyusutan & 3.129 .000 & 846.429 .000 & 8.435 .833 & 1.022 .860 \\
Pendapatan & 81.504 .600 & 72.047 .571 & 123.586 .167 & 48.000 .000 \\
Biaya tetap & 8.817 .000 & 688.429 & 13.225 .833 & 3.128 .860 \\
Biaya tidak tetap & 116.876 .000 & 54.444 .000 & 120.378 .000 & 140.326 .000 \\
Total biaya & 125.747 .000 & 61.332 .429 & 133.633 .833 & 143.455 .660 \\
Penerimaan & 207.252 .000 & 133.380 .000 & 257.220 .000 & 260.052 .000 \\
Pajak & 0 & 0 & 0 & 0 \\
Laba bersih & 207.252 .000 & 133.380 .000 & 257.220 .000 & 260.052 .000 \\
NPV & 15.385 .000 & 19.561 .000 & 97.020 .000 & 31.252 .000 \\
IRR & $20.66 \%$ & $18.52 \%$ & $22.05 \%$ & $21.72 \%$ \\
B/C Ratio & 1.64 & 2.17 & 1.92 & 2.14 \\
BEP (kg) & 10.398 .54 & 2.577 .7 & 9.00 .32 & 1.55 .1 \\
BEP (Rp) & 20.630 .232 & 10.176 .210 & 25.011 .05 & 5.751 .580 \\
PP(thun) & 0.05 & .0 .12 & 0.02 & 0.02 \\
IP & 1.031 & 0.764 & 0.578 & 0.905
\end{tabular}

Sumber: Hasil survey desa dan kuesioner (diolah)

Tabel 12. Matrix Analisis kebijakan usaha penangkapan ikan nelayan dikabupaten Aceh Barat.

\begin{tabular}{llll}
\hline Uraian & Penerimaan & Biaya Input $(\mathrm{Rp})$ & Keuntungan \\
\hline Jaring & & & \\
Harga privat & 81.504 .600 & 125.747 .000 & $(44.242 .400)$ \\
Harga social & 256.873 .000 & 72.488 .500 & 184.384 .500 \\
Divergensi & $(250.077 .950)$ & 53.258 .500 & $(140.142 .100)$ \\
Pancing & & & \\
Harga privat & 72.047 .571 & 61.332 .429 & $(10.715 .142)$ \\
Harga social & 156.000 .000 & 21.378 .600 & 134.621 .400 \\
Divergensi & $(149.996 .000)$ & 39.953 .829 & $(123.906 .258)$ \\
Gillnet & & & \\
Harga privat & 123.586 .167 & 133.633 .833 & $(10.047 .666)$ \\
Harga social & 311.725 .000 & 30.499 .000 & 281.226 .000 \\
Divergensi & $(301.426 .153)$ & 103.134 .833 & $(271.178 .334)$ \\
Pukat & & & \\
Harga privat & 48.000 .000 & 140.326 .800 & $(92.326 .800)$ \\
Harga social & 270.258 .000 & 96.235 .000 & 174.023 .000 \\
Divergensi & $(266.258 .000)$ & 44.091 .800 & $(81.696 .200)$ \\
\hline Sub Dap & & &
\end{tabular}

Sumber: Data primer dan kuesioner (diolah)

Tabel 13. Hasil analisis usaha penangkapan ikan di wilayah perairan Aceh Barat.

\begin{tabular}{|c|c|c|c|c|c|c|}
\hline \multirow{3}{*}{$\begin{array}{c}\text { Jenis alat } \\
\text { tangkap }\end{array}$} & \multicolumn{6}{|c|}{ Jenis Analisa } \\
\hline & \multirow{2}{*}{ Nilai B/C } & \multicolumn{2}{|c|}{ BEP } & \multirow{2}{*}{ PP } & \multirow{2}{*}{ IP } & \multirow{2}{*}{$\begin{array}{c}\text { Relative Share } \\
\text { Upah }\end{array}$} \\
\hline & & $\mathrm{Rp}$ & $\mathrm{Kg}$ & & & \\
\hline Jaring & 1.64 & Rp 20.630.232 & 10.398 .54 & 0.05 & 1.031 & 25.431 \\
\hline Pancing & 2.17 & Rp 10.176.210 & 2577.7 & 0.12 & 0.764 & 18.250 \\
\hline Gillnet & 1.92 & Rp 25.011.005 & 9005.32 & 0.24 & 0.578 & 27.860 \\
\hline Pukat & 2.14 & $\operatorname{Rp} 3.123,860$ & 15581 & 0.02 & 0.905 & 23.710 \\
\hline
\end{tabular}

Sumber : Data primer dan kuesioner (diolah) 
Tabel 14. Hasil analisa pendapatan nelayan dari usaha penangkapan ikan

\begin{tabular}{lllc}
\hline \multicolumn{1}{c}{ Jenis alat tangkap } & $\begin{array}{c}\text { Bagian pendapatan } \\
\text { ABK per unit } \\
(\mathrm{Rp} \mathrm{1000/thn)}\end{array}$ & $\begin{array}{c}\text { Rata-rata pendapatan } \\
\text { per nelayan } \\
(\mathrm{Rp} \mathrm{1000/thn})\end{array}$ & $\begin{array}{c}\text { Rata -rata alat tangkap } \\
\text { ABK perunit alat } \\
\text { tangkap(orang) }\end{array}$ \\
\hline Jaring & $\mathrm{Rp} 81.504 .600$ & $\mathrm{Rp} 13.584 .100$ & 6 \\
Pancing & $\mathrm{Rp} 72.047 .571$ & $\mathrm{Rp} 24.015 .857$ & 3 \\
Gillnet & $\mathrm{Rp} 123.586 .167$ & $\mathrm{Rp} 247.172 .334$ & 5 \\
Pukat & $\mathrm{Rp} 48.000 .000$ & $\mathrm{Rp} 9.600 .000$ & 5 \\
\hline
\end{tabular}

Sumber : Data primer dan kuesioner (diolah)

\section{Kesimpulan}

Hubungan antara peran LHAL dalam kehidupan masyarakat nelayan terhadap tingkat pendapatan dengan menggunakan uji korelasi spearman didapat bahwa operan LHAL dalam menyelesaikan sengketa yang terjadi antar nelayan berpengaruh nyata pada tingkat kepercayaan $5 \%$, sedangkan peran LHAL sebagai penghubung antara pemerintah dengan nelayan serta peran LHAL dalam mengurus dan menyelenggarakan upacara adat laot tidak berpengaruh nyata.

Faktor yang paling berpengaruh terhadap tingkat pendapatan nelayan dikabupaten Aceh Barat adalah tingkat pendidikan nelayan, pengalaman berusah serta jumlah anggota rumah tangga nelayan, sedangkan secara financial keseluruhan jenis alat tangkap yang digunakan nelayan cukup memberikan keuntungan dan secara absolut pendapatan rata-rata nelayan lebih banyak disebabkan karena perbedaan teknologi yang digunakan. Dan terdapat kecendrungan bahwa makin tinggi investasi modal yang dibutuhkan bagi suatu jenis alat tangkap teryata indek probabilitasnya semakin menurun.

\section{Saran}

Diharapkan pemerintah dan pihak perbankan untuk membantu permodalan dan pemebrian kredit (dalam hal ketersediaan dan kemudahan untuk meng-akses) sehingga para nelayan terlepas dari rentenir. Sedangkan usaha yang dilakukan diantaranya penguatan kelembagaan Panglima Laot melalui peningkatan intensitas komunikasi, membangun administrasi, mengefektifkan kelembagaan dan ber-upaya meningkatkan kembali pemahaman nelayan tentang hukum adat laot.

\section{Daftar Pustaka}

Adami, Y. 1995. Aspek kelembagaan Masyarakat nelayan dalam pengembangan wilayah dikabupaten Aceh Utara. Thesis Program Pascasarjana IPB.Bogor

Anonymous. 2003. Peran Hukum Adat Laot dan Panglima Laot dalam menyelesaikan sengketa nelayan di Nanggroe Aceh Darussalam (Makalah Seminar Pusat Studi keamana dan perdamaian UGM). Yogyakarta

---------. 2002. Keputusan Pertemuan Musyawarah Panglima Laot se-Provinsi Nanggroe Aceh Darussalam, Banda Aceh

Badan Pusat Stastistik Kabupaten Aceh Barat. 2001. Aceh Barat Dalam Angka.

Budiharsono, S. 2002. Teknik Analisis Pembangunan Wilayah Pesisir dan Kelautan. PT.Prandya Pratama. Jakarta

Kadariah. 2001. Evaluasi Proyek : Analisis Ekonomi. Lembaga Penerbit Fakultas EkonomiI Jakarta.

Kasmir. 2003. Studi Kelayakan Investasi. Prenada Media. Jakarta

Nya'Pha, H. 2001. Panglima Laot; Peranan dalam Lembaga Adat Laot (Menuju Hukum Adat yang berkekuatan hukum tetap). Makalah disampaikan pada lokakarya yang dilaksanakan oleh Panglima Laot se-Aceh di Sabang pada tanggal 19-21 Maret 2001.

Rifai, Zuriaty. 2002. Analisis Kelembagaan dan kondisi umum social ekonomi masyarakat perairan umum Lebak Lebung di Kabupaten Musi Banyuasin Provinsi Sumatera Selatan. Thesis Program Pascasarjana Institut Pertanian Bogor. 